\title{
Overcoming Cultural Barriers to Scholarly Communication in International Peer-Reviewed Journals
}

\author{
Lilia Raitskaya ${ }^{1}$, Elena Tikhonova ${ }^{2,3}$ \\ ${ }^{1}$ Moscow State Institute of International Relations (MGIMO University) \\ ${ }^{2}$ National Research University Higher School of Economics \\ ${ }^{3}$ Peoples' Friendship University of Russia (RUDN University)
}

\begin{abstract}
Correspondence concerning this article should be addressed to Elena Tikhonova, National Research University Higher School of Economics, 11 Pokrovsky Bulvar, Pokrovka Complex, room S313, Moscow, 109028, Russian Federation.E-mail: etihonova@hse.ru
\end{abstract}

\begin{abstract}
The editorial dwells upon the challenges L2 scientific authors have to rise to. 'Publish or perish' policy pursued globally leads to an increased international market of predatory journals in response to persisting university requirements to academics' publications in international journals. The quality issues of scholarly publications are coming to the fore, with re-focusing on skills and competencies necessary to produce research acceptable to high-tier and well-established journals. Non-Anglophone L2 writers face more barriers to English-language international periodicals than native speakers of English, as they tend to follow distinct cultural patterns of thought. Consequently, rhetorical moves and steps of scholarly texts may substantially differ from those written by Anglophone researchers. The scholarly community has to handle a growing set of problems related to L2 scholarly writing in English to ensure their successful submissions to well-established international journals.
\end{abstract}

Keywords: scholarly communication, predatory journal, academic writing, good-faith journal, international journal, IMRAD, cultural pattern of thought, rhetorical schema, moves and steps, L2 writer, topic prominence, quasi-scientific journal

\section{Introduction}

Scholarly communication embraces diverse forms and formats. As the essence and result of research are embodied in the form of scientific publication, much attention is paid to scientific communication, its efficacy and barriers that form an integral part of the research and publishing process. "Publishing a scientific manuscript in scientific journal is a way to network within the target audience" (Somashekhar, 2020). For researchers and universities, it is quality of publications that really matters. "High-quality publications remain the primary tool for describing national and individual contributions to science and society" (Lambovska \& Yordanov, 2020).

Professional and academic development as well as careers in the academia at large demand conducting research and publishing the results in international peer-reviewed journals. It has become the prevailing form of scholarly communication in the world. "...Staff on contracts, tenure track or not, have publishing norms the fulfilment of which is decisive for keeping a job in academia" (Zarkov, 2019).

"International often means European and North American, and very often English-language journals" (Zarkov, 2019). Originally, Anglophone journals published by old European, mainly British, universities, and later replenished by periodicals of American universities lay the foundation for what we all know as high-tier international journals. Thus, the bulk of most cited research articles and high-tier international journals are published in English. The latter is globally considered as a lingua franca of science and academia. Internationalisation of science and educations spurred the spread of English in those strata, though bigger and smaller nations still try to support their national and state languages in science and science publishing through their language policies. 
Language policies range from multilingualism to a bias towards national/ state languages in education and science or occasionally focusing on English as a lingua franca in science. Language policies are closely linked to the phenomena of academic multiliteracy and L2 monoliteracy. But both academic multiliteracy (writing academically in more than one language) and of L2 monoliteracy (writing for science in a language that is not your own) (Harbord, 2018) are still limited to national elites of non-Anglophone countries. A wider scholarly community in most non-Anglophone courtiers linguistically is far from writing in English at a level fit for international journals. Some non-Anglophone researchers, though monolingual or multilingual, thrust to compete for being recognised in English-language high-tier journals, as their command of English, grammatical irregularities, scarce vocabulary, occasionally wrong collocations, limited faculty of expression, surface-level errors and blunders distorting meaning, and interventions from the authors' mother tongues in communication (starting from grammar and vocabulary to text rhetoric) result in comprehensive revising, editing, and ultimately re-submission of the manuscripts by L2 authors. Flowerdew \& Wang (2016) think that as L2 authors, or as they call them 'English as Additional Language (EAL) scholarly writers', badly require English-language proofreading service, language brokers (they are very much like editors, but, in general, mainly non-Anglophone linguists), or sometimes, even academic brokers (whose function is to upgrade the content of submitted papers through some revisions and improvements) have become part of the publishing landscape. As compared with native speakers' editing services that are expensive and non-affordable for some EAL writers, academic and language brokers may support and revise would-be submissions quite efficiently. They may pinpoint such writers towards a better result.

Writing comes naturally only to some people who are able to immerse into the specific discourse of a research field on their own. Most researchers have to learn how to write scholarly texts. They have to put much effort into mimicking the style and formats of specific journals. It is important to understand that scholarly writing is not all about writing. It requires a deep professional background knowledge, scholarly logic, skills to write clearly within the cultural tradition of the language, aptitude to follow patterns of thought, typical of English. "Lack of proficiency in scientific writing results in confusing conclusions leading the manuscripts to data dumps" (Somashekhar, 2020). A scientific author must master a combination of competencies (understanding the field; writing skills; aptitude to understand, analyze and report the scientific results in the required format) (Somashekhar, 2020). Deficient proficiency may occasionally prompt some authors to look for an easier and often unreliable way of publishing their research results.

\section{Quasi-Scientific Publishing}

Scholarly publishing witnesses an unprecedented spread of so-called predatory journals. They are contrasted with traditional and good-faith journals (Edmunds \& Waldrop, 2018). In the recent years, “... the pressure of university requirements for publishing have contributed to the increased numbers of both submissions and rejections (Zarkov, 2019)" in all journals, as well as to proliferation of unscrupulous journals of low quality. Deceptive practices in such journals entail the absence of peer-review and controls over the submission quality, validity and ethics of submissions to such periodicals. The phenomenon turned up as a response to a rising demand on the scholarly publishing market spurred by 'Publish or Perish' policy pursued throughout the world. "Predatory magazines are created by unreliable publishers who, after collecting a fee, publish the submitted paper in the Open Access formula without providing substantial control" (Grzybowski, Patryn \& Sak, 2017). The policy gave rise to a trend in science, where the productivity and efficacy of scholars and researchers are assessed via the number and quality of the papers they publish in international journals, mainly indexed in Scopus and Web of Science. In addition, "a 'publish or perish' risk, resulting in the repetition of identical studies" (Ertaş \& Kozak, 2020) has substantially increased in science at large. Consequently, the quality of scholarly publications in the world is decreasing proportionately to their numerical rise (Nielsen \& Davison, 2020). It is obvious that '...there is significant linguistic variation' between articles published in predatory journals and articles published in wellestablished journals (Soler \& Wang, 2019). Articles in predatory journals deviate from linguistic standards in academic publishing, with more specialized vocabulary in good-faith journals and more words of general English in predatory periodicals (Soler \& Wang, 2019).

'Quasi-scientific', or predatory journals amounted to some 10,000 in 2016 on the Beall's List (Grzybowski, Patryn \& Sak, 2017). The threat of publishing a paper in predatory journals may result in periodicals with discontinued indexation and lower status articles. Young-career researchers or academics with low or no English-language aptitude tend to submit their papers to predatory or dubious journals more often. They may be unaware of the low ethics status of a journal they select, or think that loose reviewing or even its absence will make their submissions easier. Unfortunately, less effort on part of researchers encouraged by predatory periodicals might motivate some unscrupulous scientists. 


\section{LILIA RAITSKAYA, ELENA TIKHONOVA}

Any career in science or academia follows numerous patterns and trajectories but none stands a chance of unethical behaviour. Occasionally, publishing in predatory journals might put an end to a career in science or tarnish a researcher's integrity (D'Alessandro et al., 2020). Only "high-quality publications are at the root of researchers' prestige, recognition in science, career progression" (Lambovska \& Yordanov, 2020).

\section{What makes a good publication?}

For experienced editors and reviewers, it does not take much time to see whether the submission will survive through the revisions and evaluations or ultimately fail (DeLisi, 2019). All solid, high-quality manuscripts share the same features. For researchers, it is advisable that their writings should be up to the best international publishing and editing standards, including:

- primary criteria: novelty and unobviousness (Somashekhar, 2020);

- meaningful and relevant content (Edmunds \& Waldrop, 2018);

- relevant research methods;

- clear and concise communication style (Edmunds \& Waldrop, 2018);

- critical thinking and critical communication (Edmunds \& Waldrop, 2018);

- $\quad$ logic (Somashekhar, 2020);

- organisation (Somashekhar, 2020);

- adequate and up-to-date bibliographic basis;

- precision (Somashekhar, 2020).

The above list partly summarizes some recommendations by editors, reviewers and experienced writers. It takes L2 authors years of hard work and practice to get proficiency and meet the requirements. Academic writing skills and relevant scientific competencies are vital for writing a good paper, but to be accepted and published in top-tier journals, the theme of research must fall within the so-called topic prominence. Research themes should be relevant and interesting for a wide scholarly community.

\section{What is Topic Prominence?}

Experienced authors regularly read articles published in high-tier journals in their subject area and beyond. They are wellinformed of the recent developments and new contributions to the field. To succeed in publishing a paper in an international journal, an academic has to follow globally recognised sources indexed in Scopus, Web of Science, etc. The task of reading articles in English may challenge some authors' insufficient command of the language, but to a degree. Numerous natural language translation service programmes, both online and offline, may be of great help to them.

Another challenge for authors in the developing countries is their access to international databases, as not all scientific centres and universities have permanent subscriptions to databases and journals. National programmes of support for science and research partly solve the problems arising out of insufficient financial resources. The availability of relevant scientific information may also be provided through social networking sites like Research Gate.

The topic prominence in Scopus combines three components, including citation count, views count, and Average CiteScore. The latter unites eight components (CiteScore, CiteScore Tracker, CiteScore Percentile, CiteScore Quartiles, CiteScore Rank, Citation Count, Document Count, Percentage Cited). Researchers may define the topicality of their research by topic prominence of similar articles indexed in Scopus database.

\section{Cultural Pattern Structuring Matters}

Internationalisation of the world science is rather uneven by all criteria. Some countries entered this phase only some ten years ago. In addition, their language, linguistic traditions of scholarly writing, article genres and styles may be in some kind of contradiction with global, or literally Anglophone, science. In many non-English academic cultures at large, including those with Oriental, Slavic, Roman, etc. components, essays are very popular as an academic genre. Though, in English and most European languages, essays prevailed in science throughout the centuries, the advent of digital technologies spurred a change in structing information, including that in research articles. Too many scientific data piled in the Internet, without subtitles and clearly-cut content, can easily turn into an unrequired dump. 
Structuring and templates have come into being in response to the challenge of the ever-growing net of information. Consequently, most papers published in international journals in English tend to be well-structured under IMRAD or other similar formats. Research tradition and modern scholarly genres in non-English cultures are still preserved, with fewer interferences and influences caused by the global trends in scholarly writing. Thus, roughly speaking, L2 researchers beyond the English-speaking World with a poor command of English often face hurdles in following IMRAD and other global formats. They are not in the habit of thinking along the English-inspired structures and templates. Such academics cannot sell their ideas efficiently, blurring their essence behind arguments and theses, unconcise and vague for English-speaking and English-thinking researchers.

It is obvious that EAL or L2 authors with a non-professional command of English are prone to text structures, typical of their native languages. Such submissions are full of hypertextual links to the background ideas and concepts (e.g. like in Russian). Other languages often have patterns of thought and idea developments contrasted to English. Anglophone readers may find them too superfluous and abundant in details, or too tedious with many repetitions of arguments and theses at different levels. Similar impression is brought by L2 writers whose English is substantially interfered from their mother tongues. E.g. in Slavic countries, journals tend to receive more papers that are descriptive (Zarkov, 2019). In addition to the prevailing patterns of thought, Slavic universities were formed and scientific thought in general developed under the German academic tradition, with descriptive nature of research in social sciences and humanities at the core.

Kaplan (1966) finds that thinking patterns gravely depend on the language and culture a person belongs to. English prompts speakers/ writers towards linear and direct communication. The arguments follow the logic of a communication act. We may rarely find any going off-topic in such texts.

Latin-based languages make their users zigzag via parallel lines in communication. Russian- and other Slavic-language speakers also think and communicate moving away from the point, with unparallel zigzags. In both instances, zigzagging aims to enrich the background of the core theme of the communication, displaying cultural tradition of communicating ideas. In the Semitic languages, there are parallelisms of all kinds (synonyms, antitheses and contrasts). For Anglophone readers, scholarly texts written under interferences from those languages may occasionally be taken as the ones with broken logic and interrupted arguments. "Logic (in the popular, rather than the logician's sense of the word) which is the basis of rhetoric, is evolved out of culture; it is not universal. Rhetoric, then, is not universal either (Kaplan, 1966)".

Studying rhetoric schemas in English and comparing them with their counterparts in Russian, we see that following rhetoric moves and steps of the particular language is of great value and contribution to the quality (first of all, readability) of the texts produced by L2 writers. Efficient L2 writers are to know much about the rhetoric of English, especially the rhetoric of scholarly texts.

\section{Conclusion}

The quality of scholarly writing is on the JLE priority list, as it is the backbone of any good-faith journal. The JLE editors and reviewers do their utmost in helping JLE authors perfect their submissions.

The scholarly community may succeed in better quality papers and journals in combined efforts, overcoming the hurdles and facing the challenges. There are at least three most important directions of such work in the academia:

- researchers' personal willingness to improve skills and competencies to meet the highest research and writing standards in science;

- a comprehensive system of teaching relevant skills throughout all educational levels;

- consorted efforts of the experienced part of the academia, including editorial boards of scholarly journals, on educating and supporting young and new-career scientific writers.

\section{Conflict of interest}

The authors declare that they have no conflict of interest. 


\section{LILIA RAITSKAYA, ELENA TIKHONOVA}

\section{References}

D’Alessandro, S., Miles, M., Martínez-López, F. J., Anaya-Sánchez, R., Esteban-Millat, I., \& Torrez-Meruvia, H. (2020). Promote or perish? A brief note on academic social networking sites and academic reputation. Journal of Marketing Management, 36(5-6), 405-411. https://doi.org/10.1080/0267257X.2019.1697104

Edmunds, M.W., \& Waldrop, J. (2018). What is Scholarly Writing? The Journal for Nurse Practitioners, 14(8), A11-A12. https://doi.org/10.1016/j.nurpra.2018.08.012

Ertaş, M., \& Kozak, M. (2020). Publish or perish: The proportion of articles versus additional sections in tourism and hospitality journals. Journal of Hospitality and Tourism Management, 43, 149-156. https://doi.org/10.1016/j. jhtm.2020.03.001

Flowerdew, J., \& Ho Wang, S. (2016). Author's editor revisions to manuscripts published in international journals. Journal of Second Language Writing, 32, 39-52. https://doi.org/10.1016/j.jslw.2016.03.004

Grzybowski, A., Patryn, R., \& Sak, J. (2017). Predatory journals and dishonesty in science. Clinics in Dermatology, 35(6), 607-610. https://doi.org/10.1016/j.clindermatol.2017.07.003

Harbord, J. (2018). Language policy and the disengagement of the international academic elite. Science Editing, 5(1), 3238. https://doi.org/10.6087/kcse.115

Kaplan, R. (1966). Cultural thought patterns in intercultural education. Language Learning, 16, 1-20. https://doi. org/10.1111/j.1467-1770.1966.tb00804.x

Lambovska, M., \& Yordanov, K. (2020). Motivation of researchers to publish in high-quality journals: A theoretical framework. TEM Journal, 9(1), 188-197. https://doi.org/10.18421/TEM91-27

Nielsen, P., \& Davison, R. M. (2020). Predatory journals: A sign of an unhealthy publish or perish game? Information Systems Journal, 30(4), 635-638. doi:10.1111/isj.12289

Soler, J., \& Wang, Y. (2019). Linguistic differences between well-established and predatory journals: a keyword analysis of two journals in political science. Learned Publishing, 32(3), 259-269. https://doi.org/10.1002/leap.1244

Somashekhar, S. P. (2020). Art of scientific writing. Indian Journal of Gynaecologic Oncology, 18(2). https://doi.org/10.1007/ s40944-020-00382-y

Swales, J. (1990). Genre Analysis: English in Academic and Research Settings. Cambridge University Press.

Zarkov, D. (2019). What we do and what we don't: Paradoxes of academic writing for publishing. European Journal of Women's Studies, 26(4), 357-359. https://doi.org/10.1177/1350506819870632 